\title{
Fuzzy Analytical Hierarchy Process Method to Determine the Quality of Gemstones
}

\author{
Mochammad Sobandi Dwi Putra $\mathbb{D}^{D}$, Septi Andryana $(\mathbb{D}$, Fauziah, and Aris Gunaryati \\ Department of Informatics, Universitas Nasional, Jakarta 12520, Indonesia \\ Correspondence should be addressed to Septi Andryana; septi.andryana@civitas.unas.ac.id
}

Received 25 May 2018; Accepted 13 September 2018; Published 1 October 2018

Guest Editor: Qi Zeng

Copyright (c) 2018 Mochammad Sobandi Dwi Putra et al. This is an open access article distributed under the Creative Commons Attribution License, which permits unrestricted use, distribution, and reproduction in any medium, provided the original work is properly cited.

\begin{abstract}
The selection of quality gemstones requires a special ability to select and assess the quality of gemstones to be traded. The diversity of types of gemstones and consumers becomes an obstacle in itself when the knowledge and ability of individuals to analyze the quality of gemstones is minimal. The decision-making method used is Fuzzy Analytical Hierarchy Process (F-AHP) method which is widely used in various sectors. F-AHP is easy to adapt to many decision issues; the research proposes a decision-making system using the F-AHP algorithm to analyze the quality of gemstones. The results obtained with the use of F-AHP model in the selection of quality gemstones show the highest quality of gemstones of all stones compared, Rubi 1, with a weight value of 0.152942 .
\end{abstract}

\section{Introduction}

Many times, we are always faced with several options for the right decision-making. It is difficult to determine an accurate choice according to predetermined criteria. Decision-making issues are also experienced when selecting quality gemstones. For the gemstones entrepreneur, special skills are required to select or assess the quality of gemstones to be traded. The diversity of types of gemstones and consumer types in choosing gemstones is certainly a constraint when the data is incomplete and there is a lack of individual knowledge about analyzing the quality of gemstones.

To maintain the consistency of product quality and in accordance with the demands of the market, it is necessary to have quality control on eligible products, so that the error does not happen again. The system to be created is a solution that can assist decision-making for decision-makers in assessing and selecting quality gemstones accurately and effectively.

In previous research, several studies using the F-AHP method have been proven from several previous studies with the conclusion that the F-AHP method can be applied and effective for many problems in real life. Chien-Chang Chou and Ker-Wei Yu [1] propose a hybrid fuzzy AHP to deal with the decision-making problems in an uncertain and multiple-criteria environment choice. The F-AHP adopted by the research [2], which combines the AHP with fuzzy set theory, can not only capture the thinking logic of human beings but also focus on the relative importance of the evaluation criteria. In journal [3], the result obtained shows the best balance of performance for criteria from different categories such as physicochemical properties as well as safety, environmental, and health aspects. The assumption made in F-AHP approach is that all the criteria involved are independent of each other. However, in practice the relationship among criteria is usually complex, and there might be interdependencies.

To control the quality, we need a relevant element and method [4]; fuzzy model can be used with various mcdm methods [5]. F-AHP model is a good referral for decisionmakers [6]. The fuzzy AHP method is applicable as a control for the quality and is useful for multicriteria decision-making problems [7]. The criteria people think of are the size that makes the quality of the gemstone better but with other criteria as a comparison can make the quality of smaller stones better than larger ones [8].

By using F-AHP method we can help a decision-maker to make more efficient, flexible, and realistic decisions based 
TABLE 1: Data of gemstones containing specific gravity, color, hardness, cutting, and clarity as the main criteria. The data can be seen from the gemstone certificate.

\begin{tabular}{lccccc}
\hline & Specific gravity & Color & Hardness & Cutting & Clarity \\
\hline Rubi 1 & $4.50 \mathrm{ct}$ & AAA & $9 \mathrm{mohs}$ & Excellent & I2 \\
Rubi 2 & $1.60 \mathrm{ct}$ & AA & $9 \mathrm{mohs}$ & Excellent & SI2 \\
Rubi 3 & $0.65 \mathrm{ct}$ & $\mathrm{A}$ & $9 \mathrm{mohs}$ & Average & I1 \\
Rubi 4 & $2.25 \mathrm{ct}$ & $\mathrm{A}$ & $9 \mathrm{mohs}$ & Average & SI1 \\
Rubi 5 & $1.05 \mathrm{ct}$ & $\mathrm{B}$ & $9 \mathrm{mohs}$ & Poor & VS \\
\hline
\end{tabular}

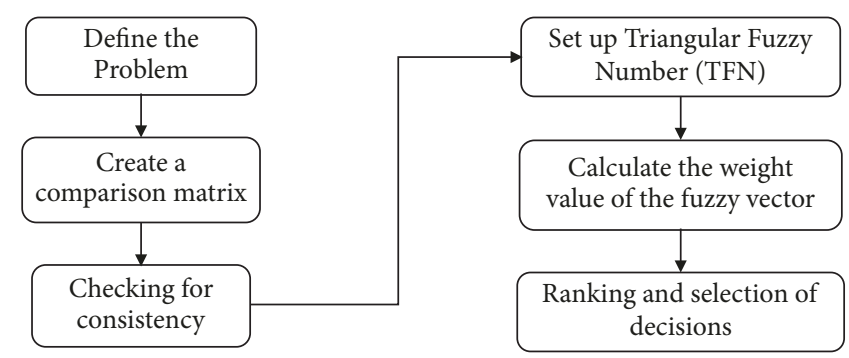

FIGURE 1: Block diagram has six steps of F-AHP phase process.

upon the available criteria and alternatives [9]. Therefore, the authors wish to apply the F-AHP method to determine the quality of gemstones.

\section{Data Availability}

The data and criteria in Table 1 were collected by consulting the director of Kantor Promosi Batu Mulia Indonesia. The data can be seen from the stone certificate issued by Kantor Promosi Batu Mulia Indonesia. Every time we buy gemstones we will get certificate of authenticity of stone; in the certificate there are criteria of stone.

\section{Materials and Methods}

Analytic Hierarchy Process (AHP) is a decision support method developed to complete problem by breaking the solution problems, grouping them, and then arranging them into a hierarchical structure. To obtain priority criteria, this method uses a comparison of criteria paired with a measurement scale that has been determined. The main input of the AHP method is the perception of experts or experts, so there is a factor of subjectivity in retrieval decision. This method also takes into account data validity with inconsistency limits [10]. However, considerable uncertainty and doubt in giving an assessment will have an impact on the accuracy of the data and the results obtained. Based on this, further theory was developed, namely, the method of Fuzzy Analytic Hierarchy Process. Fuzzy Analytic Hierarchy Process is a method of Analytic Hierarchy Process (AHP) developed with fuzzy logic theory. Fuzzy AHP method is used similar to the method of AHP. It is just that the Fuzzy AHP method sets the AHP scale into the fuzzy triangle scale to be accessed priority.

In this section, the F-AHP method was developed. The procedure used in the proposed method is described as follows.
Step 1 (define the problem and determine the desired solution (see Figure 1)). We need to define the problem according to the criteria used to determine the gemstones of quality. Specific gravity, color, hardness, cutting, and clarity are used as the main criteria for determining gemstone quality. This is some data from the gemstone certificate (see Table 1).

The weight of the stone has a unit of carat (ct); the greater the weight of a gemstone, the greater its size. Stone hardness unit is called Mohs because the name of the first person to do research on the hardness of a gemstone was Friedrich Mohs, a geologist and mineralogist from Germany in 1812. The clarity level of a gemstone is divided into IF, VVS1, VVS2, VS1, VS2, I1, I2, etc. The gemstone color level is seen from the level of clarity of color seen by the eye, given the levels of B, A, AA, $\mathrm{AAA}$, and so on. The level of cutting quality is seen from its proportional and symmetrical shape of gemstones pieces.

Step 2 (create a comparison matrix (see Figure 1)). After we know the data and criteria stone in Table 1 we need to create a comparison matrix. The matrix used is simple, has a strong position for the consistency framework, obtains other information that may be required with all possible comparisons, and is able to analyze the overall priority sensitivity for changes in consideration.

Here are the equations used to define pairwise comparisons:

$$
a_{i j}=\frac{w_{i}}{w_{j}}, \quad i, j=1,2, \ldots, n
$$

where $\mathrm{n}$ denotes the number of criteria compared, $\mathrm{W}_{\mathrm{i}}$ are weights for the $i$ criterion, and $a_{i j}$ is the ratio of the weight of the $i$ criterion and $j$.

After knowing the comparison of its criteria in Table 2, the next thing done is to normalize each column into the 
TABLE 2: Comparison of criteria, as the weighted value of each criterion.

\begin{tabular}{lccccc}
\hline Criteria & Specific Gravity & Color & Hardness & Cutting & Clarity \\
\hline Specific Gravity & 1 & 3 & 2 & 3 & 3 \\
Color & $1 / 3$ & 1 & 3 & 1 & 3 \\
Hardness & $1 / 2$ & $1 / 3$ & $1 / 3$ & 1 & 3 \\
Cutting & $1 / 3$ & $1 / 2$ & $1 / 3$ & 3 \\
Clarity & $1 / 3$ & $1 / 3$ & & $1 / 3$ \\
\hline
\end{tabular}

TABLE 3: Ratio index.

\begin{tabular}{ccccccccccc}
\hline $\mathrm{n}$ & 1 & 2 & 3 & 4 & 5 & 6 & 7 & 8 & 9 & 10 \\
\hline $\mathrm{RI}$ & 0,00 & 0,00 & 0,58 & 0,90 & 1,12 & 1,24 & 1,32 & 1,41 & 1,45 & 1,49 \\
\hline
\end{tabular}

matrix form by dividing each value in the column $i$ and row $j$ with the largest value in column $\mathrm{i}$.

$$
a_{i j}=\frac{a_{i j}}{\max a_{i j}}, \quad \forall i, j
$$

Then the results of the matrix normalization from Table 2 are obtained as follows:

$$
\left[\begin{array}{ccccc}
0,4 & 0,58 & 0,3 & 0,321 & 0,231 \\
0,133 & 0,193 & 0,45 & 0,214 & 0,231 \\
0,2 & 0,064 & 0,15 & 0,3214 & 0,231 \\
0,133 & 0,096 & 0,05 & 0,107 & 0,231 \\
0,133 & 0,064 & 0,05 & 0,035 & 0,072
\end{array}\right]
$$

Step 3 (checking for consistency (see Figure 1)). The comparison of the consistency index with a random generator (RI) value is listed in Table 3 set by Saaty [10]. This value depends on the matrix order $n$.

Consistency is expected to be near perfect to produce a decision that is close to valid.

Here is the equation used to calculate the value of consistency.

First we must recognize the value of the eigenvector which is the weighted value of the criterion. To calculate the eigenvector, we use the following equation:

$$
w_{i}=\frac{\widehat{a}_{i}}{n}, \quad \forall i
$$

$w_{i}$ is the eigen vector, where $\hat{a}_{i}$ is the sum of the matrix normalization values and is divided by the number of criterion (n)

The largest eigenvalue is the number of times multiplying the number of columns with the main eigenvector (see Table 4). So it can be obtained by the equation

$$
\begin{aligned}
\lambda m a k s= & \left(\sum G M_{11-n 1} \times \bar{X} 1\right)+\ldots \\
& +\left(\sum G M_{1 n-n i} \times \overline{X n}\right)
\end{aligned}
$$

TABLE 4: Eigenvector on criteria.

\begin{tabular}{lc}
\hline Criteria & eigenvector \\
\hline Specific Gravity & 0,3665 \\
Color & 0,2443 \\
Hardness & 0,1933 \\
Cutting & 0,1236 \\
Clarity & 0,0720 \\
\hline
\end{tabular}

$$
\begin{aligned}
\lambda \text { maks }= & (0,3665 \times 2,5)+(0,2443 \times 5,667) \\
& +(0,1933 \times 6,6667) \\
& +(0,1236 \times 9,333)+(0,0720 \times 13) \\
\lambda \text { maks }= & 5,474
\end{aligned}
$$

After obtaining maximum lambda value, the value of CI can be determined.

$$
C I=\frac{\lambda m a k s-n}{n-1}
$$

where CI is the consistency index and maximum lambda is the largest eigenvalue of the n-order matrix.

$$
\begin{aligned}
& C I=\frac{5,474-5}{5-1} \\
& C I=0,1185
\end{aligned}
$$

If the value of $\mathrm{CI}$ is zero (0), this means the matrix is consistent. If the value of CI obtained is greater than $0(\mathrm{CI}>$ 0 ), then the limit of inconsistency applied by Saaty is tested. Testing is measured using Consistency Ratio (CR), i.e., index value (Table 3 ), or comparison between $\mathrm{CI}$ and RI.

$$
C R=\frac{C I}{R I}
$$

The RI value used is in accordance with the order $\mathrm{n}$ matrix. If the CR of a smaller matrix is $10 \%(0,1)$, this means that the inconsistency of each opinion is considered acceptable.

$$
\begin{aligned}
& C R=\frac{0,1185}{1,12} \\
& C R=0,1058
\end{aligned}
$$


TABLE 5: TFN scale.

\begin{tabular}{lccc}
\hline TFN Scale & L & M & U \\
\hline 1 & 1 & 1 & 1 \\
2 & 0,5 & 1 & 1,5 \\
3 & 1 & 1,5 & 2 \\
4 & 1,5 & 2 & 2,5 \\
5 & 2 & 3 & 3 \\
6 & 2,5 & 3,5 & 3,5 \\
7 & 3 & 4 & 4 \\
8 & 3,5 & 4,5 & 4,5 \\
9 & 4 & 1 & 4,5 \\
0,5 & 0,666667 & 0,666667 & 0,5 \\
0,333333 & 0,5 & 0,5 & 0,666667 \\
0,25 & 0,4 & 0,4 & 0,5 \\
0,2 & 0,333333 & 0,333333 & 0,4 \\
0,166667 & 0,285714 & 0,285714 & 0,333333 \\
0,142857 & 0,25 & 0,25 & 0,285714 \\
0,125 & 0,222222 & 0,222222 & 0,25 \\
0,111111 & 0,222222 & & \\
\hline
\end{tabular}

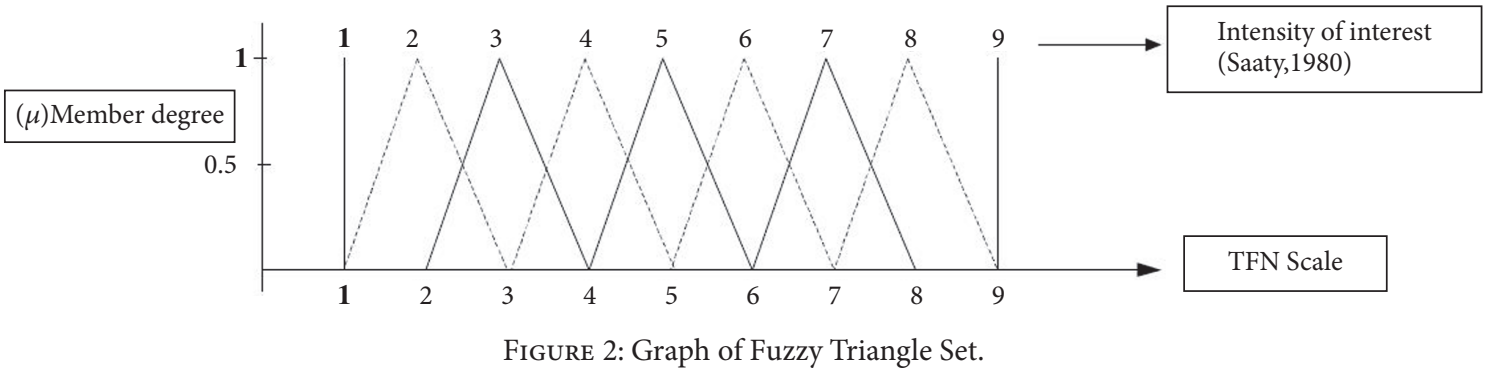

The consistency value of 0.1058 is equivalent to $10 \%$ inconsistency; this value can still be tolerated because the consistency value index must be less than 0.1 .

Step 4 (set up Triangular Fuzzy Number (TFN) (see Figure 1)). The F-AHP scale has three values, namely, the lowest value (lower, L), middle value (median, $\mathrm{M}$ ), and highest value (upper, $U$ ). So each fuzzy set will be divided into 2 (see Figure 2), except for the same comparison set, or can be seen on the TFN scale (see Table 5).

Based on the index (see Table 5), the comparison value in Table 2 will be made into a TFN set (see Table 6).

Step 5 (calculate the weight value of the fuzzy vector (see Figure 1)). After the AHP comparison value is transformed to F-AHP scale value, fuzzy synthesis value is calculated. The process to get fuzzy synthesis value is shown using equation of the following formula:

$$
S i=\sum_{j=1}^{m} M_{g i}^{j} X \frac{1}{\left[\sum_{i=1}^{n} \sum_{j=1}^{m} M_{g i}^{j}\right]}
$$

Information:
$S i=$ fuzzy synthesis value

$\sum_{j=1}^{m} \boldsymbol{M}_{\boldsymbol{g} i}^{j}=$ summing the cell value in that column starting from column 1 in each row matrix

$$
\mathrm{i}=\text { row }
$$

$\mathrm{j}=$ column

After the comparison of fuzzy synthesis values (see Table 7), we will get the defuzzification ordinate value $\left(d^{\prime}\right)$. From the above calculation, we can calculate the values of $\mathrm{v}$ and $\mathrm{d}^{\prime}$. To calculate $\mathrm{V}^{\prime}$ we use the equation of the following formula.

$V(M 2 \geq M 1)$

$$
= \begin{cases}1, & \text {, if } m 2 \geq m 1 \\ 0, & \text {,if } l_{1} \geq u_{2} \\ \frac{l_{1}-u_{2}}{\left(m_{2}-u_{2}\right)-\left(m_{1}-l_{1}\right)^{\prime}} & \text {, etc }\end{cases}
$$

Calculating the value of the fuzzy vector weight $\left(\mathrm{W}^{\prime}\right)$, calculation of the fuzzy weight value is shown using the equation of the following formula

$$
d^{\prime(A i)}=\min V(S i>S k)
$$


TABLE 6: TFN set of criteria; each value in the criteria comparison (see Table 2) is changed to TFN referring to the TFN scale.

\begin{tabular}{lccccccccccccccccc}
\hline & \multicolumn{3}{c}{ Specific Gravity } & \multicolumn{4}{c}{ Color } & \multicolumn{3}{c}{ Hardness } & \multicolumn{4}{c}{ Cutting } & \multicolumn{3}{c}{ Clarity } \\
& $\mathrm{L}$ & $\mathrm{M}$ & $\mathrm{U}$ & $\mathrm{L}$ & $\mathrm{M}$ & $\mathrm{U}$ & $\mathrm{L}$ & $\mathrm{M}$ & $\mathrm{U}$ & $\mathrm{L}$ & $\mathrm{M}$ & $\mathrm{U}$ & $\mathrm{L}$ & $\mathrm{M}$ & $\mathrm{U}$ \\
\hline Specific Gravity & 1 & 1 & 1 & 1 & 1,5 & 2 & 0,5 & 1 & 1,5 & 1 & 1,5 & 2 & 1 & 1,5 & 2 \\
Color & 0,5 & 0,666667 & 1 & 1 & 1 & 1 & 1 & 1,5 & 2 & 0,5 & 1 & 1,5 & 1 & 1,5 & 2 \\
Hardness & 0,666667 & 1 & 2 & 0,5 & 0,666667 & 1 & 1 & 1 & 1 & 1 & 1,5 & 2 & 1 & 1,5 & 2 \\
Cutting & 0,5 & 0,666667 & 1 & 0,666667 & 1 & 2 & 0,5 & 0,666667 & 1 & 1 & 1 & 1 & 1 & 1,5 & 2 \\
Clarity & 0,5 & 0,666667 & 1 & 0,5 & 0,666667 & 1 & 0,5 & 0,666667 & 1 & 0,5 & 0,666667 & 1 & 1 & 1 & 1 \\
\hline
\end{tabular}

TABLE 7: Synthesis value.

\begin{tabular}{lcc}
\hline \multicolumn{3}{c}{ Synthesis Value } \\
\hline $\mathrm{L}$ & $\mathrm{M}$ & $\mathrm{U}$ \\
0,125 & 0,246 & 0,439 \\
0,111 & 0,215 & 0,387 \\
0,115 & 0,215 & 0,413 \\
0,101 & 0,183 & 0,362 \\
0,083 & 0,139 & 0,258 \\
\hline
\end{tabular}

TABLE 8: Criteria weight value, the result of calculation which contains the weight value of each criterion.

\begin{tabular}{lc}
\hline criteria & Weight \\
\hline Specific Gravity & 0,279088 \\
Color & 0,249106 \\
Hardness & 0,251526 \\
Cutting & 0,220279 \\
Clarity & 0,1546 \\
\hline
\end{tabular}

collecting ordinate values that have been previously obtained, as below.

$$
\sum W^{\prime}=(v s k 1, v s k 2, \ldots, v s k n)
$$

Normalization of vector weight values is obtained by the equation of the following formula,

$$
W^{\prime}=\left(d^{\prime}(A 1), d^{\prime}(A 2), \ldots, d^{\prime}(A n)\right) \mathrm{T}
$$

Step 6 (ranking and selection of decisions (see Figure 1)). Next is to do an alternative value calculation where the alternative settlement measures are the same as the completion steps on the criteria. Each alternative element's weight value (see Table 8) will be calculated by the weight of the criteria element and will be directed to get the decision result.

\section{Result and Discussion}

The built system consists of several menus that are the stages in running the decision support system. The first thing to do is login first. To be able to use this system we need to login. After login, we will enter into the main menu. On the main page the F-AHP algorithm and any data needed to start the system process are explained. After that alternative data and criteria are entered into the system. The gemstone data we have need to be input into the alternate data input page according to

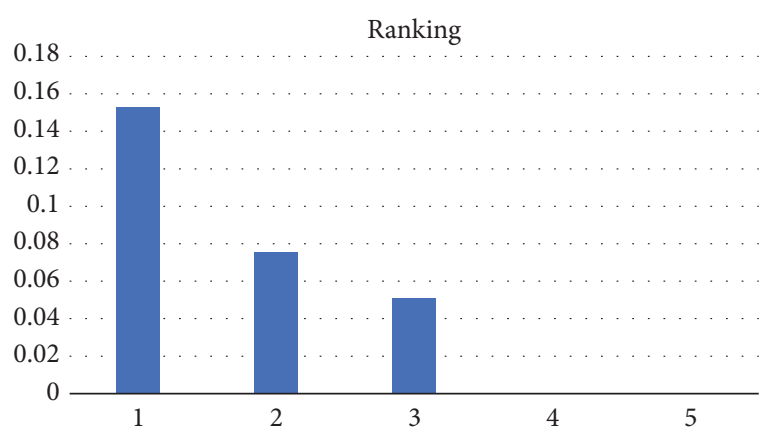

FIGURE 3: Ranking graph: ranking is derived from the result of alternate weight matrix by weight of criterion.

the criteria along with the criteria data we input into the input data page criteria. The next thing to do is to provide a comparison of the criteria and the value of alternative comparison to each criterion. After all has been done, next we can do the following process. In the process page we can see the value of criteria comparison and TFN set of criteria. When the process is completed, this will result in the ranking of each alternative; the decision-maker can determine which gemstones are qualified from the gemstones being compared. From the ranking results in Figure 3 and Table 9, it can be concluded that alternative 1 has the most optimum weight value compared with other alternatives. Therefore, a decision can be made that Rubi 1 is the highest-quality gemstone of all stones compared.

\section{Conclusion}

The conclusion of this research is as follows: we created a system that can assist decision-making in assessing and choosing quality gemstones accurately and effectively by using F-AHP algorithm.

The focus on the decision of the system is more on the decision of stones based on the same type of stone name; this is because, for the decision system to be more appropriate and relevant for use as a consideration in decision-making, it is impossible to compare one stone with stones of different types, not in the same class quality, so the end result of the system is based on the classification of the type of stone name.

As shown in Figure 3 we obtained the result by using the F-AHP model in the selection of quality gemstones Rubi 1 with a weight value of 0.152942 , Rubi 2 of 0.075731 , Ruby 3 of 0.050075 , and Ruby 4 and Rubi 5 of 0 . This weighting value 
TABLE 9: Value of alternative calculation result on criteria.

\begin{tabular}{lcccccc}
\hline & Specific Gravity & Color & Hardness & Cutting & Clarity & Total \\
\hline Rubi 1 & 0,548005 & 0,389588 & 0,25 & 0,42711 & 0,427683 & 0,152942 \\
Rubi 2 & 0,270062 & 0,531613 & 0,25 & 0,57289 & 0,491956 \\
Rubi 3 & 0,181933 & 0,028674 & 0,25 & 0 & 0,080361 & 0,075371 \\
Rubi 4 & 0 & 0,050125 & 0,25 & 0 & 0 & 0 \\
Rubi 5 & 0 & 0 & 0,25 & 0 & 0 \\
\hline
\end{tabular}

indicates that a gemstone of the highest quality is Rubi 1 with a weight value of 0.152942 of all stones compared.

\section{Data Availability}

The data used to support the findings of this study are available from the corresponding author upon request.

\section{Conflicts of Interest}

The authors declare that they have no conflicts of interest.

\section{References}

[1] Chien-Chang Chou and Ker-Wei Yu, "Application of a New Hybrid Fuzzy AHP Model to the Location Choice," Mathematical Problems in Engineering, vol. 2013, Article ID 592138, 12 pages, 2013.

[2] H.-Y. Wu, G.-H. Tzeng, and Y.-H. Chen, "A fuzzy MCDM approach for evaluating banking performance based on Balanced Scorecard," Expert Systems with Applications, vol. 36, no. 6, pp. 10135-10147, 2009.

[3] J. Ooi, M. A. B. Promentilla, R. R. Tan, D. K. S. Ng, and N. G. Chemmangattuvalappil, "Integration of Fuzzy Analytic Hierarchy Process into multi-objective Computer Aided Molecular Design," Computers \& Chemical Engineering, vol. 109, pp. 191202, 2018.

[4] J.-C. Tu and C.-L. Hu, "Applying the Fuzzy Analytic Hierarchy Process to Construct the Product Innovative Service System of Wedding Photography Apparel," Mathematical Problems in Engineering, vol. 2015, 2015.

[5] M. Shaverdi, "Application of Fuzzy AHP Approach for Financial Performance Evaluation of Iranian Petrochemical Sector," Procedia Computer Science, pp. 995-1004.

[6] R.-H. Chiu, L.-H. Lin, and S.-C. Ting, "Evaluation of green port factors and performance: a fuzzy AHP analysis," Mathematical Problems in Engineering, vol. 2014, Article ID 802976, 12 pages, 2014.

[7] L. Wang, J. Chu, and J. Wu, "Selection of optimum maintenance strategies based on a fuzzy analytic hierarchy process," International Journal of Production Economics, vol. 107, no. 1, pp. 151163, 2007.

[8] S.-H. Tsaura, T.-Y. Chang, and C.-H. Yen, “The evaluation of airline service quality by fuzzy MCDM," Tourism Management, vol. 23, no. 2, pp. 107-115, 2002.

[9] . Kaur, "Selection of Vendor Based on Intuitionistic Fuzzy Analytical Hierarchy Process," Advances in Operations Research, vol. 2014, Article ID 987690, 10 pages, 2014.

[10] T. L. Saaty and K. P. Kearns, Analytical Planning The Organization of Systems, Pergamon Press, 1985. 


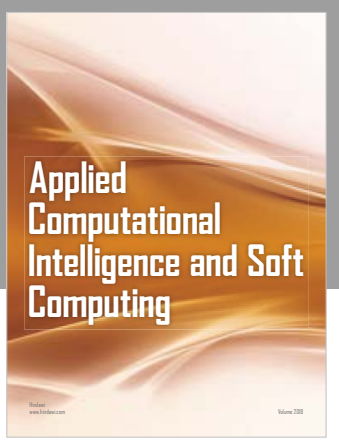

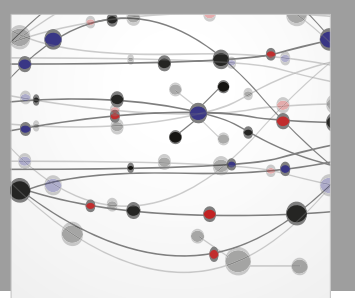

The Scientific World Journal
Submit your manuscripts at

Computing
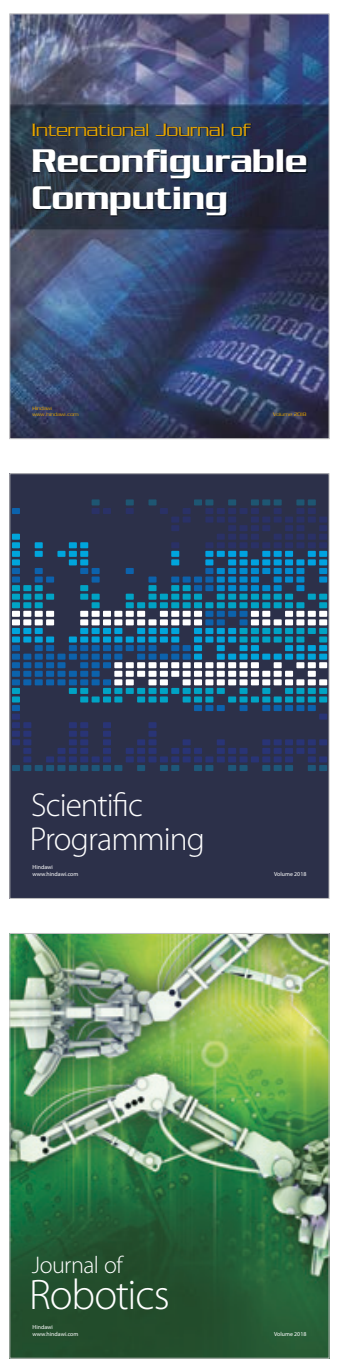

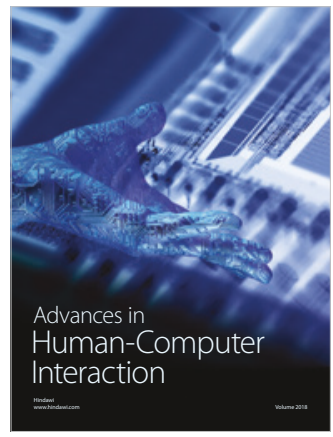

Human-Compute

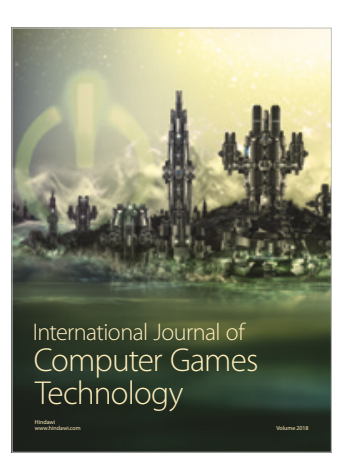

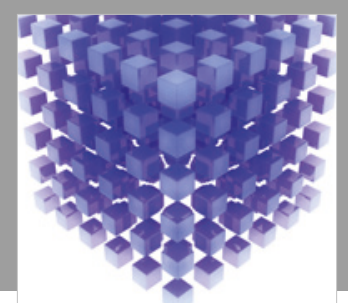

Mathematical Problems in Engineering

\section{Engincering}
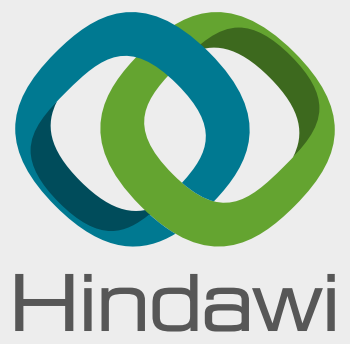

www.hindawi.com
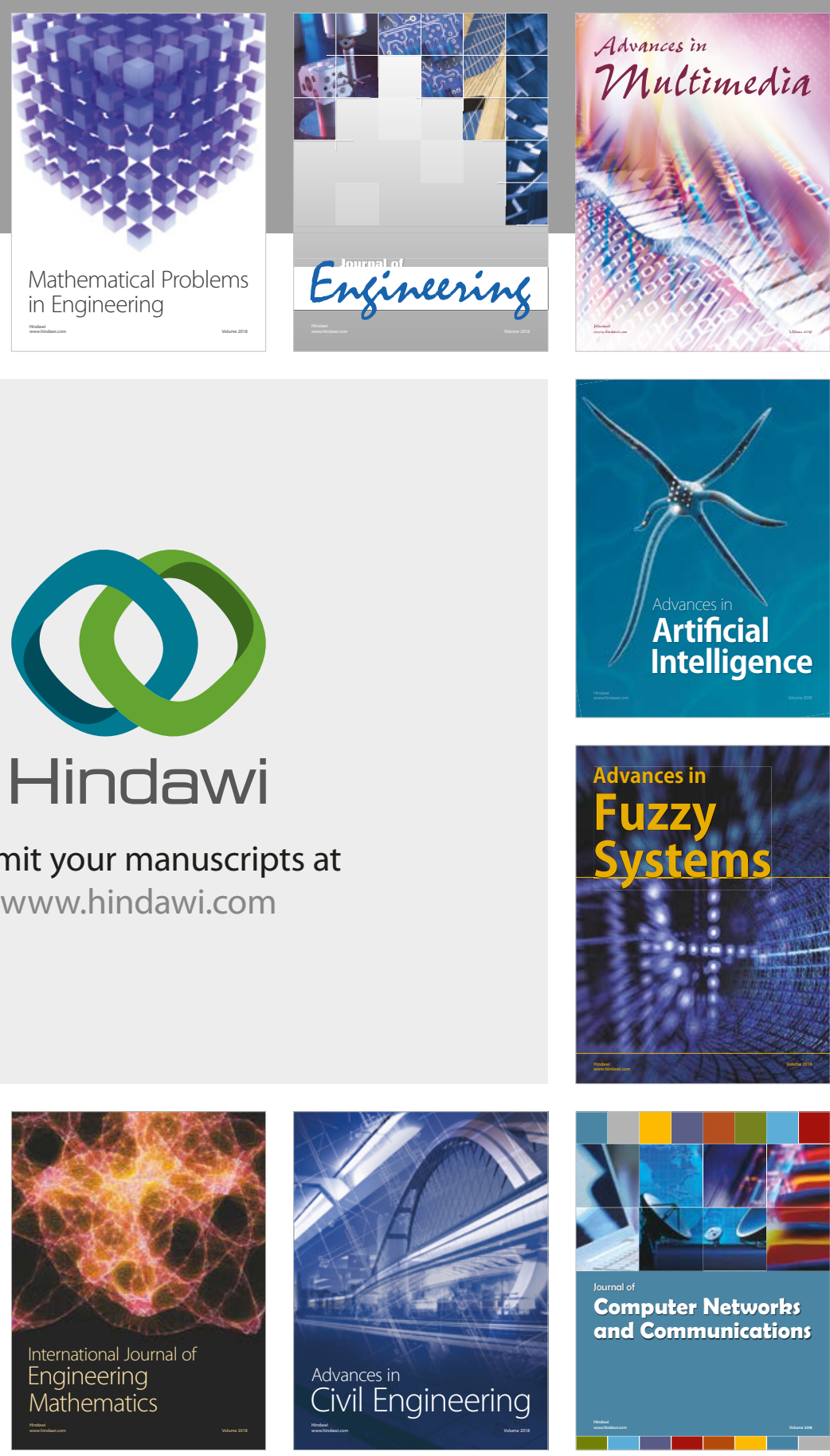

Computer Networks and Communications

Multimedia
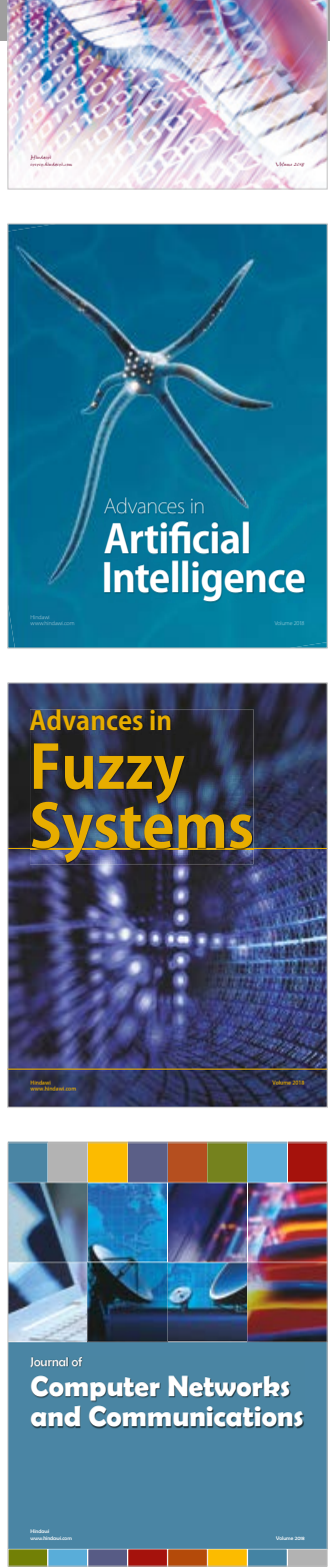

Advances in

Modelling \&

Simulation

in Engineering

interaction

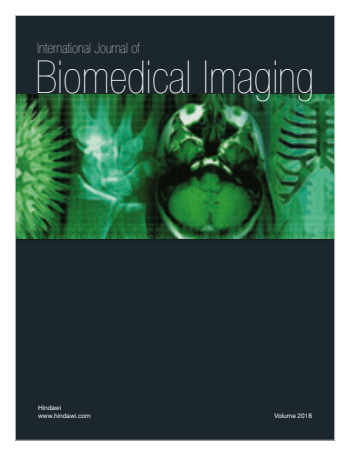

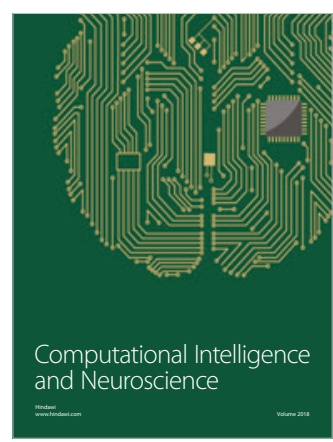

